J. Lake Sci. (湖泊科学), 2014, 26(2): 243-252

http: //www. jlakes. org. E-mail : jlakes@niglas.ac.cn

(C) 2014 by Journal of Lake Sciences

\title{
鄱阳湖国家级自然保护区食块茎鸟类种群数量与水位的关系"
}

陈 冰 ${ }^{1,2}$, 崔 鹏 ${ }^{2 * *}$, 刘观华 ${ }^{3}$, 李风山 ${ }^{4}$, 伍旭东 ${ }^{3}$, 吴建东 ${ }^{3}$, 曾南京 ${ }^{3}$, 赵 娜 $^{5}$, 徐海根 ${ }^{2}$

( 1 : 南京师范大学生命科学学院, 南京 210046)

( 2 :环境保护部南京环境科学研究所,南京 210042)

(3:江西鄱阳湖国家级自然保护区管理局,南昌 330038)

(4: 国际鹤类基金会,威斯康辛州 53913)

( 5 : 水利部中国科学院水工程生态研究所水利部水工程生态效应与生态修复重点实验室,武汉 430079)

摘 要: 以 4 种食块茎鸟类一一白鹤 (Grus leucogeranus)、白枕鹤 (Grus vipio)、鸿雁 (Anser cygnoides)、小天我 (Cygnus columbianus) 为研究对象, 分析越冬候鸟种群数量与鄱阳湖保护区内湖泊水位变化的关系. 2003-2007 年越冬季节,采用直 接计数法调查鸟类的种群数量, 通过非参数回归分析鸟类种群数量与水位之间的关系. 结果表明, 虽然 4 种食块茎鸟类的 种群数量最高值分布在不同水位,但峰值水位差异较小, 且种群数量与水位关系的总体趋势呈现一致性. 随着保护区内 湖泊水位的下降,鸟类种群数量呈现先增长后减少的倒 $\mathrm{V}$ 字形趋势. 在水位由 $16.0 \mathrm{~m}$ 降至 $14.8 \mathrm{~m}$ (吴淞高程) 的过程中, 鸟 类种群数量随着湖泊水位下降逐步增加达到最高峰; 在水位由 $14.8 \mathrm{~m}$ 降至 $13.5 \mathrm{~m}$ 的过程中,鸟类种群数量随着水位下降 而减少. 当鄱阳湖水位处于 $14.5 \sim 15.5 \mathrm{~m}$ 之间时, 食块茎鸟类的种群数量较高, 其种群数量最高点出现在水位 $14.8 \mathrm{~m}$ 左 右. 2003-2005 年 3 个年度鸟类种群数量与水位的关系相似, 呈现出先增多后减少的单峰趋势, 峰值水位均位于 14.75 $14.90 \mathrm{~m}$ 之间, 2006 和 2007 年平均水位升高,鸟类种群数量分布的峰值水位也高于前 3 年, 峰值水位出现在 $15.25 \mathrm{~m}$ 附 近. 由于受到良好保护, 大湖池和沙湖鸟类种群数量与水位的关系稳定, 而梅西湖未呈现出有规律的变化趋势. 研究表明 在本研究区域中,水位在 $14.5 \sim 15.5 \mathrm{~m}$ 之间 4 种食块茎鸟类的种群数量较高, 该研究结果对鄱阳湖国家级自然保护区水 位管控具有指导意义.

关键词: 水鸟; 种群数量; 鄱阳湖;水位

\section{Relationships between changing water levels and numbers of wintering tuber-eating birds in Poyang Lake National Nature Reserve}

CHEN Bing ${ }^{1,2}$, CUI Peng ${ }^{2}$, LIU Guanhua ${ }^{3}$, LI Fengshan ${ }^{4}$, WU Xudong ${ }^{3}$, WU Jiandong ${ }^{3}$, ZENG Nanjing ${ }^{3}$, ZHAO $\mathrm{Na}^{5} \&$ XU Haigen ${ }^{2}$

(1: College of Life Sciences, Nanjing Normal University, Nanjing 210046, P. R. China)

(2: Nanjing Institute of Environmental Sciences, Ministry of Environmental Protection, Nanjing 210042, P. R. China)

(3: Jiangxi Poyang Lake National Nature Reserve, Nanchang 330038, P. R. China)

(4: International Crane Foundation, Wisconsin 53913, USA)

(5: Key Laboratory of Ecological Impacts of Hydraulic-Projects and Restoration of Aquatic Ecosystem of Ministry of Water Resources, Institute of Hydroecology, Ministry of Water Resources and Chinese Academy of Sciences, Wuhan 430079 , P. R. China)

Abstract: Population numbers of four tuber-eating bird species(Grus leucogeranus, Grus vipio, Anser cygnoides and Cygnus columbianus) were surveyed and water levels were recorded to analyze the relationships between changing water levels and bird population numbers in Poyang Lake National Nature Reserve. During the winters ( from October to next March) of 2003 - 2007, the population

* 国家自然科学基金项目(31101651) 资助. 2013-04-07 收稿;2013-08-12 收修改稿. 陈冰( 1987 ),女,硕士研 究生; E-mail: yishan2007123@126.com.

** 通信作者;E-mail: cuipeng1126@163.com. 
numbers of the four tuber-eating birds were surveyed by direct counting method, and the relationship between water levels and population numbers was analyzed by using non-parametric regression method in SAS. The results showed that the changes of population numbers of the four species with the fallen of water levels appeared consistent. With sustainable fall of water level, the bird population first increased and then declined showing an inverted V-shape. When water level changed from $16.0 \mathrm{~m}$ to $14.8 \mathrm{~m}$ ( Wusong Elevation), the population numbers increased with the fall of water level. However, the bird population decreased when water level fell from $14.8 \mathrm{~m}$ to $13.5 \mathrm{~m}$. Higher population numbers occurred at water levels between $14.5 \mathrm{~m}$ and $15.5 \mathrm{~m}$. The highest population number occurred at about $14.8 \mathrm{~m}$. The changes of population numbers of 2003-2005 in the winter showed similar unimodal patterns, with highest numbers occurred at $14.75-14.90 \mathrm{~m}$. In the winter of 2006 and 2007 , with the rise of the average water levels, the water level of peak population numbers rose, occurred at about $15.25 \mathrm{~m}$. The relationship of water levels and population numbers were relatively stable at Dahuchi and Shahu, for these two lakes were under well protected, while in Meixihu, there was no significant trend in the changes of population numbers and water levels. The result helps guiding the water level management for Poyang Lake National Nature Reserve.

Keywords: Waterbirds; population numbers; Lake Poyang; water level

水鸟是湿地生态系统的重要组成部分, 其种群多样性与分布受多种因素的共同影响, 包括食物资源丰 富度、湿地面积大小、人为干扰程度、水深等 ${ }^{[1-6]}$. 其中水深是影响水鸟生境选择的主要因子,水鸟在喙长、腿 长、体型大小等方面的差异决定了它们对食物类型和受食水深的需求 ${ }^{[7-8]}$. 通常水鸟主要选择水陆交错带的 浅水区、泥滩和草洲作为受食地, 并且水深的变化对水鸟种群的多样性有重要影响 ${ }^{[9-14]}$. 以往关于水深与水 鸟多样性关系的研究主要集中在鸟类物种利用水位方面, 如某个物种利用的最适宜水位, 可以利用的水位 范围等 ${ }^{[15-18]}$. 部分研究报道了在一定的水深范围内, 水深与水鸟多度呈负相关关系 ${ }^{[19-20]}$. Bancroft 等对 4 种 路鹳类游禽的种群数量与水位和植被关系的研究表明, 其研究区域内路鹳类对水位的利用存在一个极限水 位, 在低于这个水位时, 鹭鹳类的种群数量与水位呈显著的正线性相关关系 ${ }^{[3]}$. Boertmann 等研究了 5 种游 禽种群数量与水位的关系, 在其研究区域的水位范围内, 5 种游禽种群数量与水位呈正相关关系, 该研究还 通过曲线模拟计算了 5 种游禽的最适宜水位, 为合理调控水位提出了建议 ${ }^{[4]}$. Holm 等研究发现食底栖动物 类群的鸟类和植食性鸟类对水位变化有不同的反应, 随着水位上升, 食底栖类群鸟类种群数量减少, 而植食 性鸟类种群数量增加 ${ }^{[13]}$. 可以看出, 在不同类型的湿地, 不同生活史类型的物种类群对水位变化具有不同的 反应.

鄱阳湖是国际重要湿地, 同时也是我国长江中下游地区乃至东亚地区最大和最重要的候鸟越冬地. 每 年在鄱阳湖越冬的水鸟总数在 50 万只以上, 世界上近 $98 \%$ 的白鹤 (Grus leucogeranus)、50\% 的白枕鹤 (Grus vipio) 和 $60 \%$ 的鸿雁 (Anser cygnoides) 在鄱阳湖越冬 ${ }^{[21-23]}$. 此外, 鄱阳湖也是长江流域最大的通江性湖泊, 受 长江和江西境内五河 (赣江、抚河、信江、饶河和修河) 相互作用, 鄱阳湖水位变化非常显著, 年内变幅超过 $10 \mathrm{~m}^{[24-25]}$. 从湖岸边到湖心, 随水深的变化, 水生植被形成湿生、挺水、浮叶、沉水 4 个植被带. 在冬季, 水位 下降, 形成众多的浅水洼地 (浅水湖) 和洲滩以及出露滩地上存留的大量水生生物残留体, 为越冬候鸟提供 了广泛的受食选择 ${ }^{[26]}$. 夏少霞等对鄱阳湖不同水位情景下的越冬水鸟适宜生境面积变化情况的研究表明, 随着水位的升高, 栖息地面积呈现出先微弱上升, 后显著下降的过程, 持续的低水位和高水位都会对在浅水 区和泥滩地生存的候鸟造成负面影响, 从而影响水鸟的种群数量 ${ }^{[26,31]}$.

为了合理调控鄱阳湖国家级自然保护区内湖泊的水位, 为越冬候鸟提供充足的食物资源, 保护鄱阳湖 众多的珍稀濒危鸟类, 本文以鄱阳湖区域以植物块茎为主要食物的白鹤、白枕鹤、鸿雁和小天鹅为研究对 象, 分析了鄱阳湖国家级自然保护区大湖池、沙湖和梅西湖水位变化与这 4 种鸟类种群数量的关系.

\section{1 研究地点与方法}

\section{1 研究地点概况}

鄱阳湖 $\left(28^{\circ} 22^{\prime} \sim 29^{\circ} 45^{\prime} \mathrm{N}, 115^{\circ} 47^{\prime} \sim 116^{\circ} 45^{\prime} \mathrm{E}\right)$ 是中国目前最大的淡水湖, 地处江西省的北部, 长江中 下游南岸. 盛水期湖面水位约 $21 \mathrm{~m}$, 在雨季最高水位期 (4-9 月, 降雨多集中于 $4-6$ 月), 当湖口 (鄱阳湖与 长江交汇处) 水位为 $21.80 \mathrm{~m}$ 时, 湖体面积为 $3955 \mathrm{~km}^{2}$. 随着鄱阳湖水位的不断下降, 江河逐渐显露, 星罗棋 
布的子湖泊与鄱阳湖主湖分离. 各子湖泊由浅水湖、泥滩、草洲等组成, 丰富的湿地资源为雁鸭类、鹤类等水 鸟提供了良好的栖息环境, 吸引了大量的越冬候鸟 ${ }^{[27]}$. 鄱阳湖国家级自然保护区面积为 $224 \mathrm{~km}^{2}$, 由大湖池、 沙湖等 9 个子湖泊形成, 本次研究的地点为保护区 9 个湖泊中的 3 个: 大湖池 $\left(29^{\circ} 6^{\prime} \mathrm{N}, 115^{\circ} 56^{\prime} \mathrm{E}\right)$ 、沙湖 $\left(29^{\circ} 11^{\prime} \mathrm{N}, 115^{\circ} 55^{\prime} \mathrm{E}\right)$ 和梅西湖 $\left(29^{\circ} 13^{\prime} \mathrm{N}, 116^{\circ} 03^{\prime} \mathrm{E}\right)$ (图 1). 其中大湖池和沙湖受到良好保护, 人为干扰小, 能 真实地表达自然状况下的鸟类种群数量状况, 但梅西湖为渔产养殖水体, 且不受保护区直接管辖, 人为干扰 较大. 3 个湖泊水位变化差异明显,各具代表性.

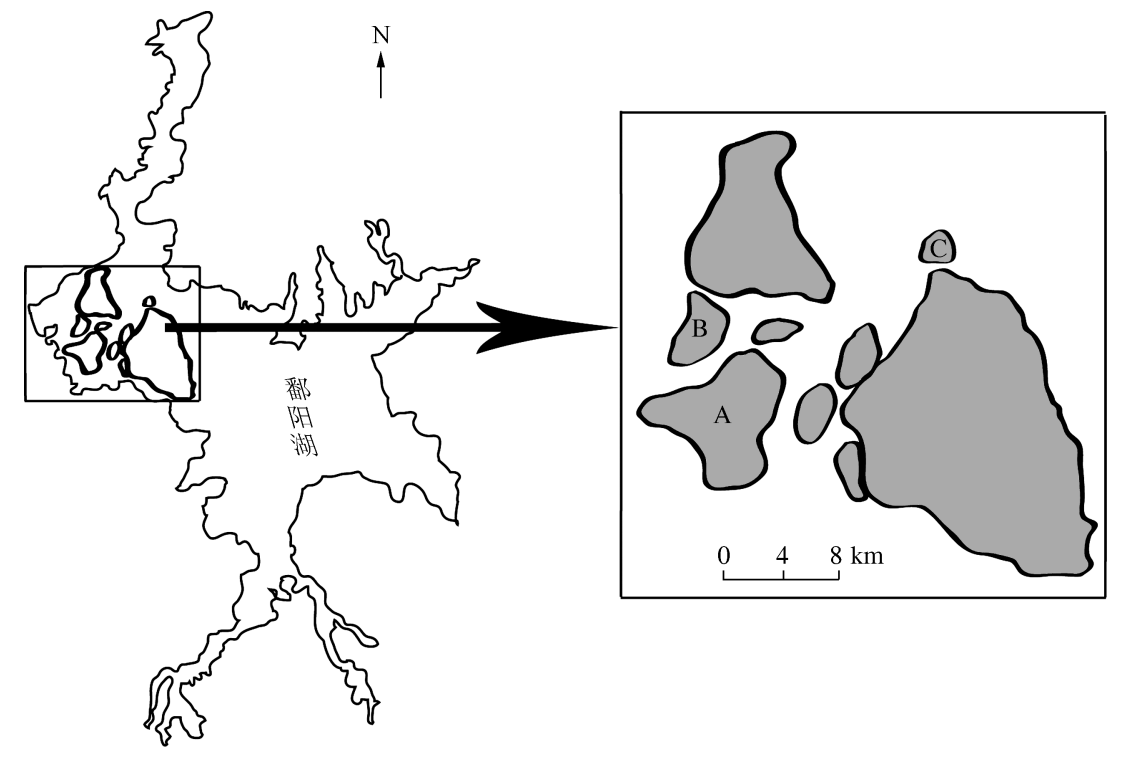

图 1 鄱阳湖国家级自然保护区大湖池 $(A)$ 、沙湖 $(B) 、$ 梅西湖 $(\mathrm{C})$ 示意图 (左图: 鄱阳湖主湖区;右图:鄱阳湖国家级自然保护区 9 个主要湖泊)

Fig. 1 Location of Dahuchi(A), Shahu(B) and Meixihu(C) in Poyang Lake National Nature Reserve

\section{2 野外调查}

1.2.1 水位记录 鄱阳湖国家级自然保护区核心区的大湖池、沙湖和梅西湖 3 个湖泊在闸口位置都设置水 位标志杆. 2003-2007 年 5 个越冬季节,每年的 10 月至次年 3 月间,每月的 $8 、 18$ 和 28 日对鄱阳湖国家级自 然保护区核心区的大湖池、沙湖和梅西湖闸口水位进行记录 (本文记录的水位采用基准均为吴淞高程). $2007-2008$ 年度越冬季节, 由于梅西湖标江杆损坏, 未能记录该年度水位.

1.2.2 鸟类调查 2003-2007 年 5 个越冬季节,每年的 10 月至次年 3 月间,每月的 8 日、18 日和 28 日对白 鹤、鸿雁和小天鹅的种群数量进行调查. 调查在能见度高的时间进行,一般在 $10: 00$ 至 16:00. 若遇见调查日 的能见度很差 (例如雨天), 则顺延往后进行调查. 调查采用直接计数法进行. 每个湖泊选择 $1 \sim 2$ 个固定的 样点,利用 $60 \times$ 单筒和 $10 \times$ 双筒望远镜进行观测. 对于集群较大 ( $>1000$ 只) 的鸟类物种,将大的集群分为 $10 、 20$ 或 50 只的小群体, 分别计数.

1.2.3 数据分析 在 Excel 中采用多元回归模拟了 5 年平均水位的变化趋势及鸟类种群数量在各湖泊的变化趋 势. 在 SAS 软件中采用非参数回归 (Non-parametric regression) 分析水位与鸟类物种多度的关系, 回归分析在 PROC LOESS 模块中进行 ${ }^{[28-29]}$. 每个湖泊从最低水位至最高水位, 以 $2 \mathrm{~cm}$ 为间隔划分等级,对每个等级内水位对 应的鸟类种群数量求平均值, 以此种群数量平均值进行后续水位与种群数量关系的分析. 在进行按年度和 按湖泊的分析时, 由于数据量变小,直接采用调查数据进行分析,没有按 $2 \mathrm{~cm}$ 水位等级进行处理. 非参数回 归的分析中,软件自动选择最优模型. 由于翻阳湖越冬水鸟种群数量自迁徙到达至迁徙离开,种群数量呈现 先逐渐增多、后逐步减少的趋势, 呈抛物线分布, 因此, 分析中设置 option DEGREE $=2(\text { 阶数 }=2)^{[29-30]}$. 


\section{2 结果}

\section{1 水位变化特征}

在本研究时间范围内, 最高记录水位为梅西湖的 $17.16 \mathrm{~m}$, 最低水位也出现在梅西湖, 为 $13.56 \mathrm{~m} .3$ 个 湖泊水位的平均值差异较小, 大湖池最低, 为 $15.07 \mathrm{~m}$, 梅西湖最高, 为 $15.18 \mathrm{~m}$. 大湖池和沙湖的年度间水位 变化较小, 大湖池基本保持稳定, 沙湖平均水位逐年增高. 梅西湖年度间水位差异较大 (图 $2 \mathrm{~A}$ ). 大湖池和沙 湖 18 个调查日的水位变化均较小, 尤其是 12 月至次年 3 月, 水位稳定在 $15.00 \mathrm{~m}$ 左右. 梅西湖水位变化大, 尤其是 1-3 月的 9 个调查日水位差异达到近 $2 \mathrm{~m}$ (图 2B).
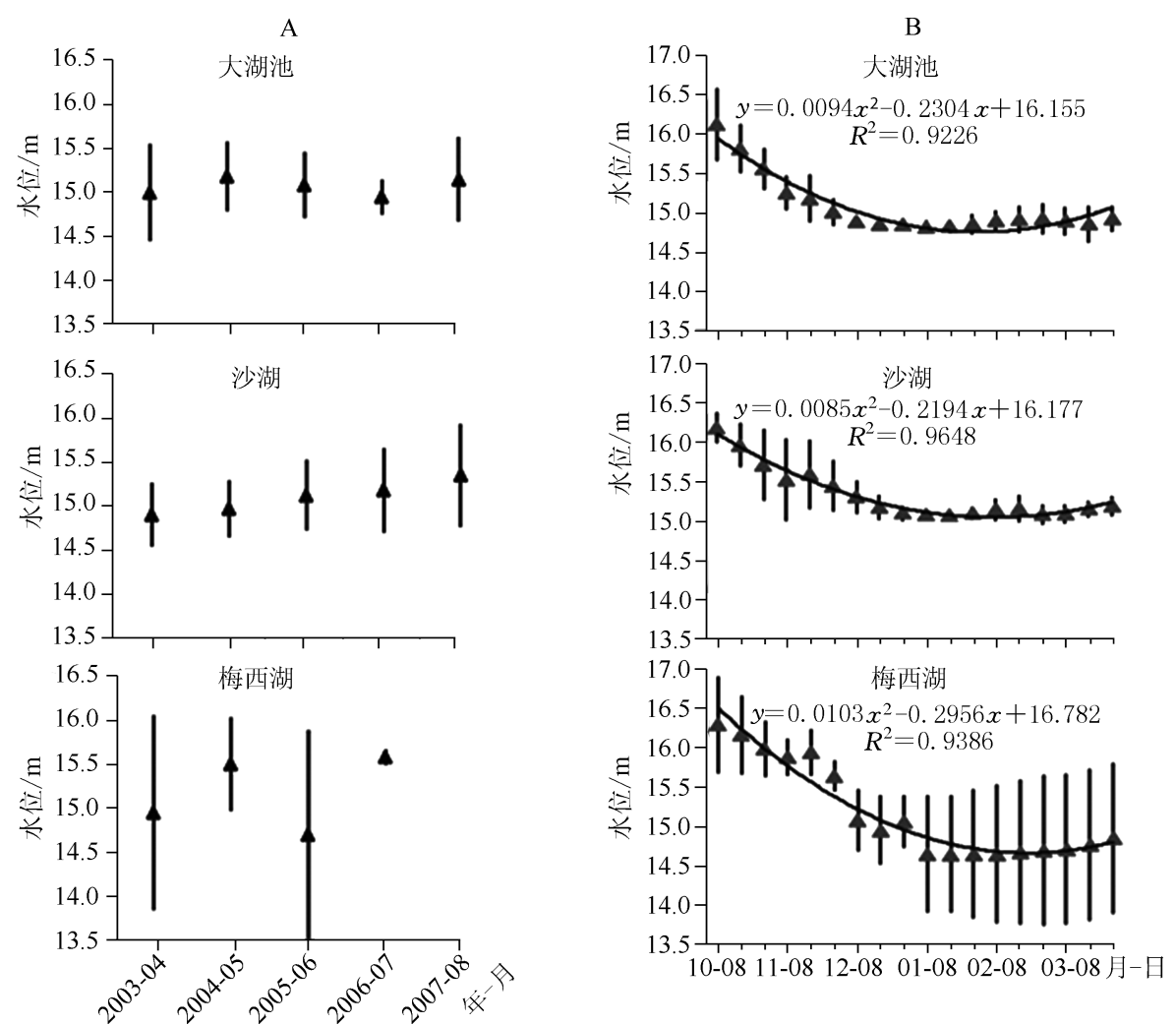

图 2 大湖池、沙湖和梅西湖年度间 $(\mathrm{A})$ 和年度内 $(\mathrm{B})$ 的水位变化

Fig. 2 Intra-year (A) and inter-year(B) changes of water levels of Dahuchi, Shahu and Meixihu

\section{2 乌类种群数量变化特征}

4 种鸟类种群数量总体上都呈现先增多后减少的趋势. 其中白鹤和白枕鹤在大湖池种群数量峰值与沙 湖中出现峰值的时间基本一致, 而鸿雁与小天鹅的种群数量峰值在大湖池出现较早, 出现在 11 月, 在沙湖 的峰值出现在 12 月. 大湖池的鸟类种群数量最高峰主要集中在 11 月下旬 12 月上中旬. 沙湖白鹤主要集中 出现在 12 月上旬及 1 月中旬, 白枕鹤主要集中出现在 11 月下旬至 12 月上旬和 1 月中旬, 鸿雁与小天鹅的 种群数量峰值主要集中出现在 12 月中下旬. 梅西湖中鸿雁与小天鹅种群数量峰值出现在 11 月上中旬, 其他 时间种群数量均较低, 白鹤与白枕鹤种群数量变化未呈现出明显的规律 (图 3).

\section{3 水鸟种群数量与湖泊水位的关系}

4 种食块茎水鸟总种群数量呈单峰分布 (图 4A). 当保护区湖泊水位为 $16 \mathrm{~m}$ 时, 种群数量接近 0 . 随着水 位逐渐下降至 $15.5 \mathrm{~m}$, 水鸟种群数量开始急剧增多, 在水位约为 $14.8 \mathrm{~m}$ 时达到数量峰值. 随着水位进一步 下降, 水鸟种群数量也呈现逐渐下降趋势, 降至水位约为 $14.0 \mathrm{~m}$ 时, 种群数量又趋近于 0 . 较高种群数量对应 

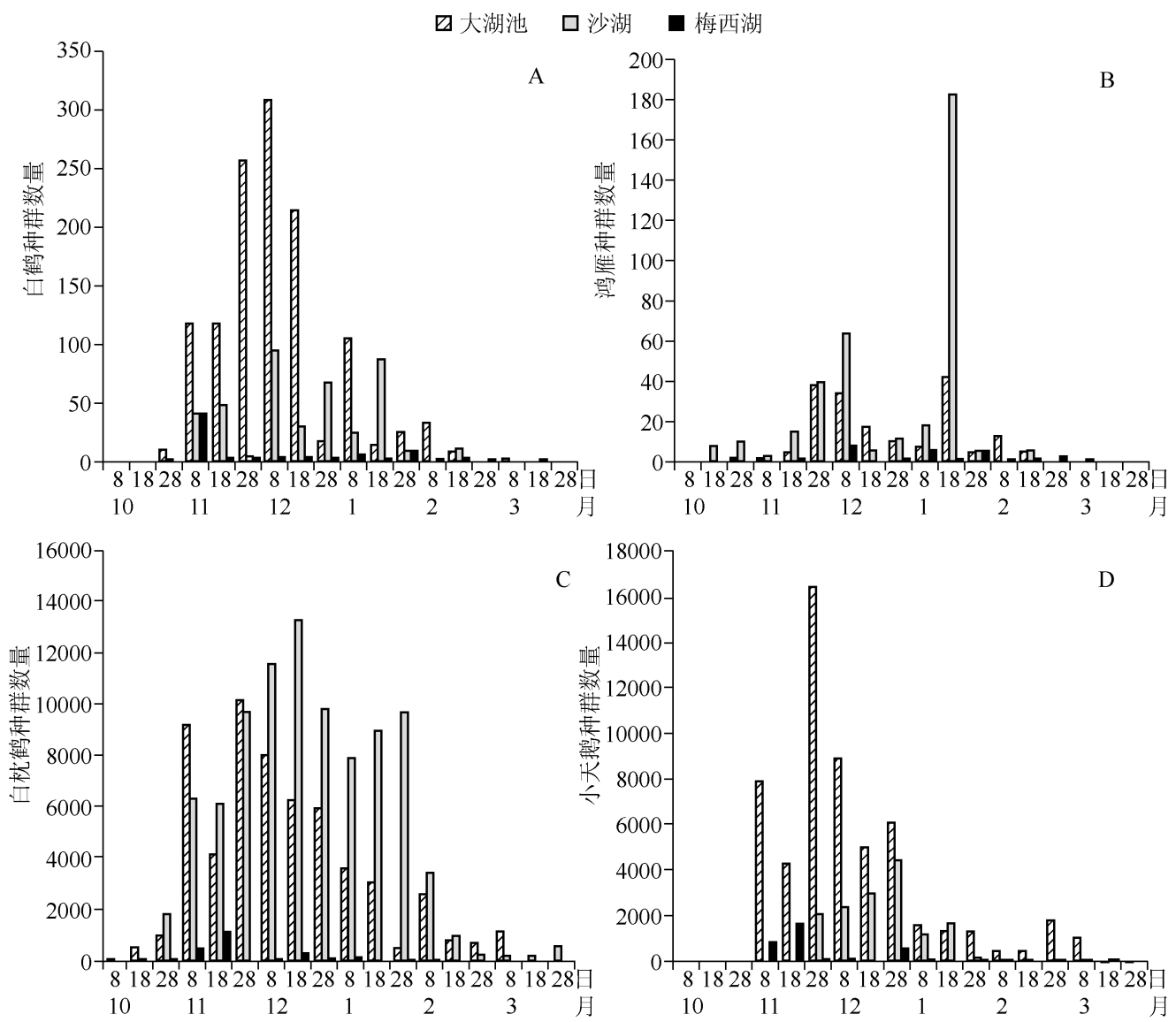

图 3 2003-2007 年鄱阳湖国家级自然保护区 3 个湖泊中 4 种食块茎水鸟种群数量的变化特征

Fig. 3 Changes of populations of four tuber-eating bird species at three lakes from 2003 to 2007 in Poyang Lake National Nature Reserve

的水位为 $14.5 \sim 15.0 \mathrm{~m}$ 之间. 本研究所选 4 种水鸟的种群数量变化趋势呈现一致性, 均呈单峰分布, 高种群数 量集中分布在湖泊水位 $14.5 \sim 15.5 \mathrm{~m}$ 之间 (图 4B E). 两种鹤类主要分布在 $14.5 \sim 15.5 \mathrm{~m}$ 之间, 鸿雁和小 天鹅主要分布在 $14.7 \sim 15.7 \mathrm{~m}$ 之间, 峰值数量均出现在约 $14.8 \mathrm{~m}$, 鸿雁和小天鹅的分布水位区间和峰值水 位均略高于两种鹤类.

\section{4 水鸟种群数量与不同年份水位变化的关系}

对 5 个不同年度 4 种水鸟种群数量随水位变化的分析表明,2003-2004、2004-2005、2005-2006 年 3 个年度水鸟种群数量与水位变化的关系相似, 均表现出随着水位下降, 种群数量呈现先增多后减少的单峰 趋势, 种群数量峰值均出现在 $14.75 \sim 14.90 \mathrm{~m}$ 之间, 当水位升至 $15.5 \mathrm{~m}$ 左右时, 种群数量趋近于零. 20062007 年种群数量没有明显变化趋势, 水位在 $14.75 \sim 15.5 \mathrm{~m}$ 之间均有大量水鸟分布, 峰值数量出现在 $15.25 \mathrm{~m}$ 附近. 2007-2008 年种群数量随着水位的下降, 呈现出先增多后减少的单峰趋势, 数量峰值也出现在 $15.25 \mathrm{~m}$ 左右. 可以看出, 年际间水位变化对种群数量变化的影响并不明显, 但从 2006-2007 和 2007-2008 2 年种群数量峰值出现的水位高于前 3 年可以看出, 随着平均水位的提高, 种群数量分布高峰也呈现出向高 水位移动的趋势 (图 5).

\section{5 水鸟种群数量与不同湖泊水位变化的关系}

大湖池的鸟类主要集中分布在水位为 $14.5 \sim 15.0 \mathrm{~m}$ 之间, 两种鹤类峰值数量出现在 $14.8 \mathrm{~m}$ 左右, 鸿雁 和小天鹅峰值数量出现在约 $15.2 \mathrm{~m}$. 沙湖 4 种鸟类主要分布在水位 $14.7 \sim 15.5 \mathrm{~m}$ 之间, 鸟类种群数量变化 
无明显规律. 梅西湖鸟类种群数量少, 变化没有明显规律 (图 6).
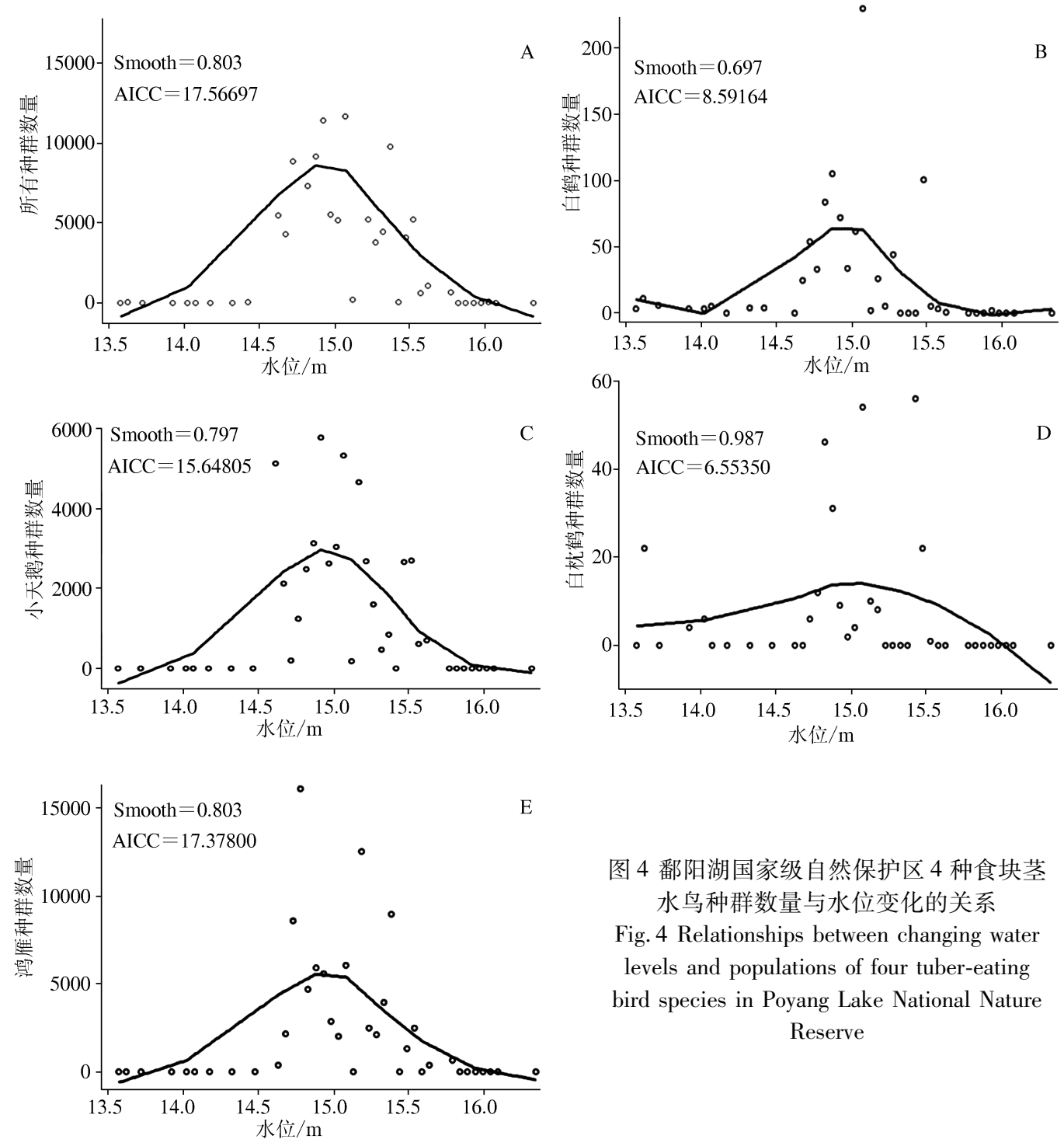

图 4 鄱阳湖国家级自然保护区 4 种食块茎 水鸟种群数量与水位变化的关系

Fig. 4 Relationships between changing water levels and populations of four tuber-eating bird species in Poyang Lake National Nature Reserve

\section{3 讨论}

湿地生态系统对水环境因子有着独特的依赖性, 水文变化过程直接影响着湿地生态系统的湿地类型、 结构和组成, 决定着湿地生物的生长和分布. 水鸟栖息地的选择主要受到食物来源的影响, 栖息地面积和水 位变化是影响水鸟多样性和丰富度的重要因素 ${ }^{[31]}$. 由于水鸟取食受到鸟的腿长、鲒长、颈长以及取食地的限 制,湿地水深低于 $1 \mathrm{~m}$ 的区域如水陆过渡带对鸟类的多样性和丰富度尤为重要 ${ }^{[32]}$.

本文对水位和鸟类种群数量关系的分析主要是在鄱阳湖国家级自然保护区内大湖池、沙湖和梅西湖 3 个湖泊展开, 由于国家级自然保护区在地势上与鄱阳湖其他区域不尽相同, 本文的分析结果并不能用于指 导整个鄱阳湖区域的水位管控, 但由于鄱阳湖国家级自然保护区是鄱阳湖区域最重要的候鸟集中分布 地 ${ }^{[22]}$, 因此,本文的分析结果对于鄱阳湖国家级保护区的水位管控具有重要的指导意义. 

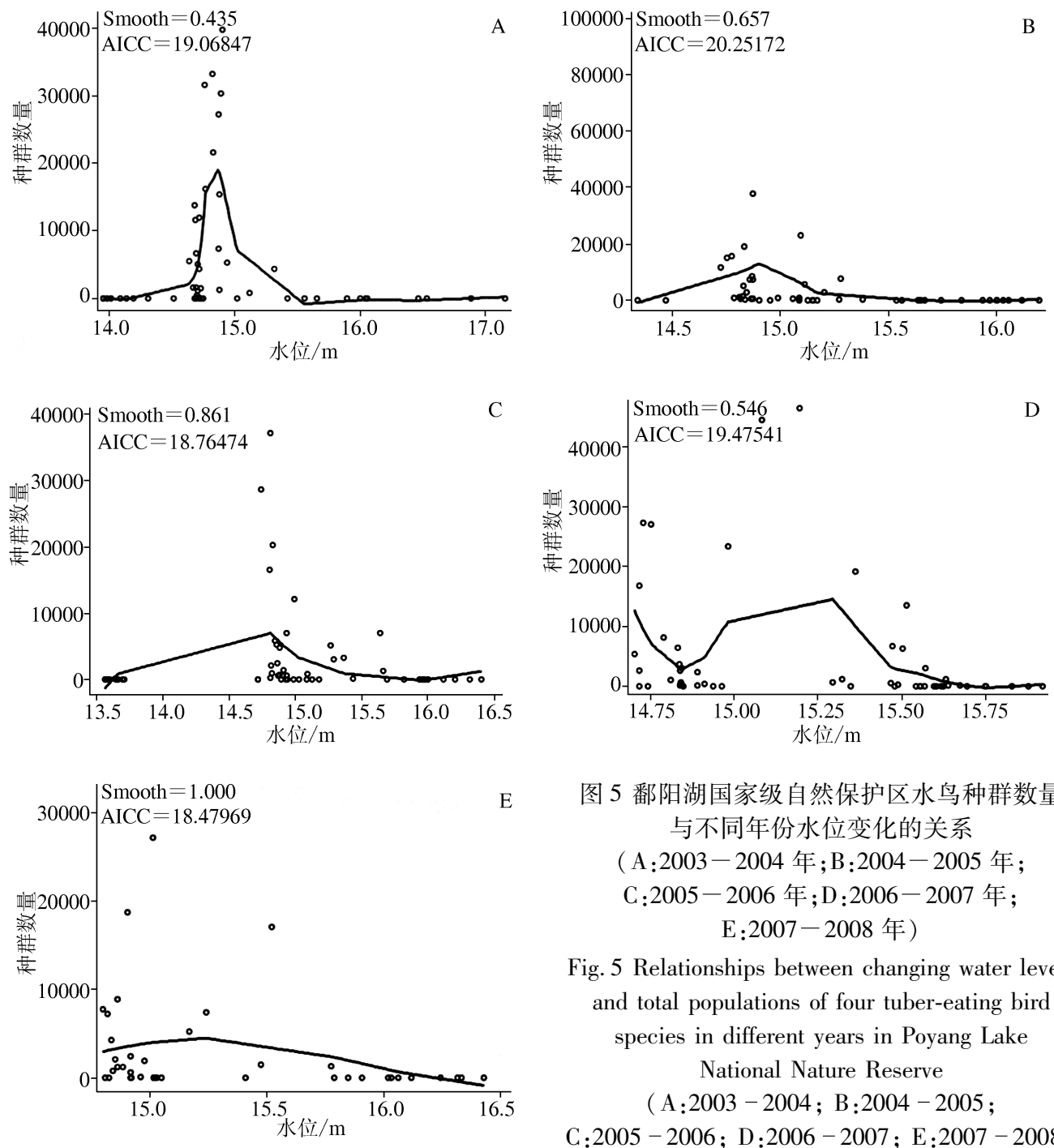

图 5 鄱阳湖国家级自然保护区水鸟种群数量 与不同年份水位变化的关系

（A:2003-2004 年; B :2004-2005 年; C:2005-2006 年; D :2006-2007 年; E:2007-2008 年)

Fig. 5 Relationships between changing water levels and total populations of four tuber-eating bird species in different years in Poyang Lake National Nature Reserve ( A:2003-2004; B:2004-2005; C:2005-2006; D:2006-2007; E:2007-2008)

\section{1 水位-生境面积 - 种群数量}

鄱阳湖是典型的过水性吞吐型湖泊,水位有明显的季节性变化. 刘成林等对鄱阳湖的水位变化对候鸟 栖息地的影响做了系统的观测和分析, 发现水位越高水陆过渡带面积越小,鸟类的生存空间越小 ${ }^{[33]}$. 每年 10 月初, 即水鸟迁徙前期,一方面许多越冬水鸟仍在迁徙途中, 尚未到达保护区, 导致湖区内观测到水鸟数 量稀少; 另一方面此时保护区内各湖水位较高, 在 $16.0 \mathrm{~m}$ 左右波动,适宜鸟类受食的草洲尚未出露, 浅水区 的面积也相对较小 ${ }^{[26]}$, 尚不能为已经到达的水鸟提供良好的受食和栖息环境,因此表现在这 3 个湖泊中的 种群数量趋近于 0 ; 在 10 月底和 11 月初, 各湖泊水位开始逐步下降至 $15.5 \mathrm{~m}$ 以下, 碟形湖与主湖区逐渐断 开直接的水流联系, 形成孤立的水域, 碟形湖周边更多的泥滩地外露, 水陆过渡带面积越来越大, 泥滩和草 洲渐渐出露 $^{[34]}$, 各种越冬水鸟纷纷到此受食和栖息, 水鸟数量急剧增加. 1-3 月份, 各湖泊水位逐步下降并 稳定在 $14.5 \mathrm{~m}$ 左右, 此时, 以苦草( Vallisneria spiralis)、黑藻 (Hydrilla verticillata)、马来眼子菜( Potamogeton malaianus ) 为主的沉水植被带达到白鹤等食块茎鸟类的适宜受食水深范围, 大量鸟类集中受食 ${ }^{[34]}$. 随着水 位进一步下降,即 3 月份以后,部分碟形洼地内湖逐渐干涸,适宜栖息地面积减少,栖息地资源竞争激烈, 部 分候鸟开始逐渐离开鄱阳湖区往繁殖地迁徙. 

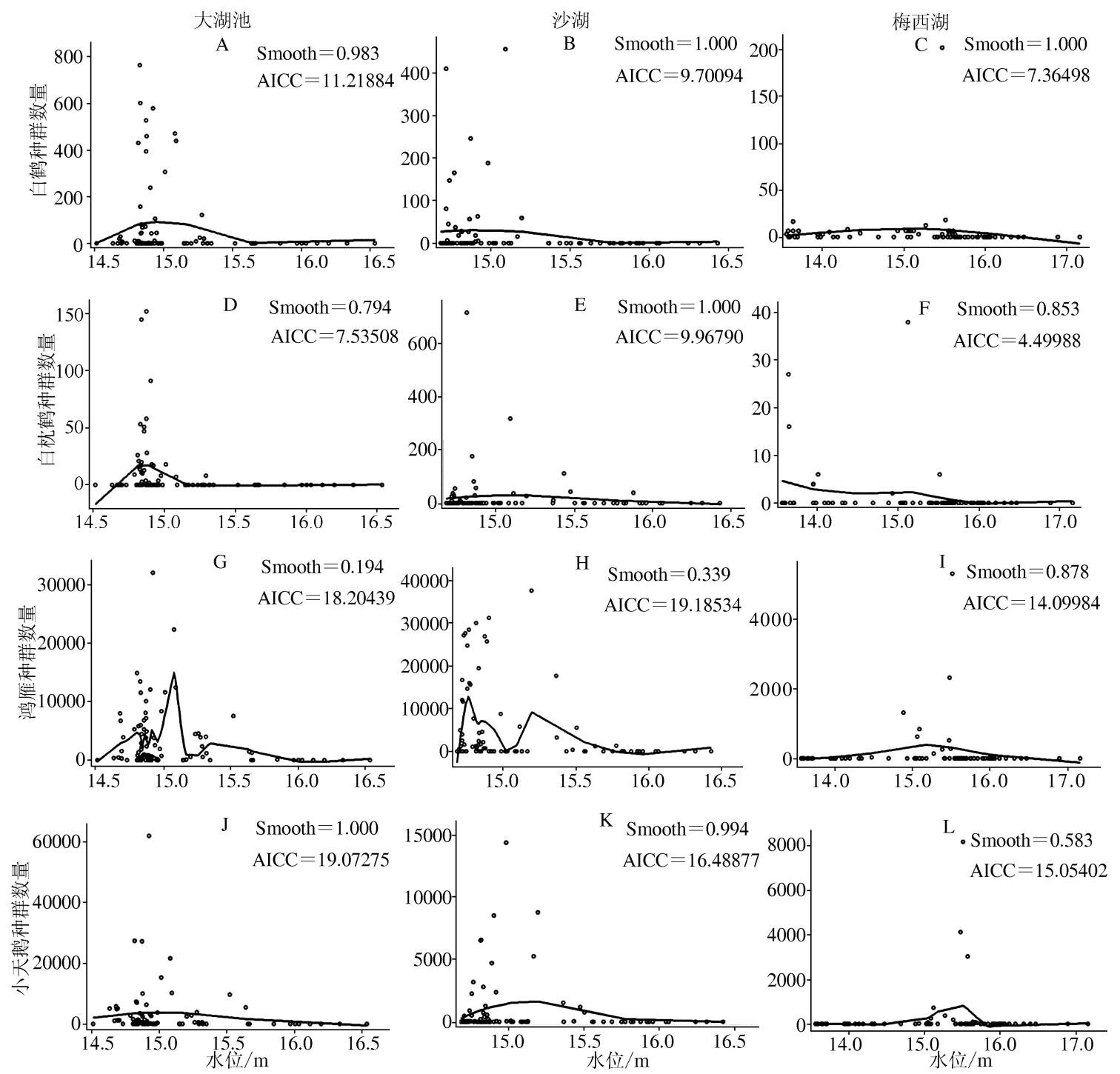

图 6 鄱阳湖国家级自然保护区水鸟种群数量与不同湖泊水位变化的关系

Fig. 6 Relationships between changing water levels and populations of four tuber-eating bird species in Poyang Lake National Nature Reserve

\section{2 水位一食物资源一种群数量}

鄱阳湖湖底较平坦, 水陆过渡带随着枯水期水位下降而移动, 稀疏草滩向沼泽、泥滩向浅水依次转移, 不断形成新的食物丰富的候鸟栖息地. 各种植物都有其特定的水分生态位, 由此决定植物群落沿水分梯度 分布格局 ${ }^{[31]} .16 \mathrm{~m}$ 的高水位下, 鄱阳湖呈现的主要湿地类型为高滩地, 植被以芦荻群落和苔草群落为主 ${ }^{[31]}$, 4 种食块茎鸟类的食物资源稀少, 鸟类数量很低; 随着水位逐渐下降, 出现了更多的水陆过渡带,适合受食的 栖息地面积增大, 并且浅碟形洼地逐渐与主湖体分离, 出现了大面积的以苦草、马来眼子菜等块根茎为主要 食物的鸟类的适宜受食生境, 此时保护区内的食块茎水鸟数量达到峰值; 随着水位进一步下降, 由于候鸟大 规模集中采食, 食物资源减少, 鸟类种群数量下降.

本研究所选的 4 种鸟类, 食物来源均以沉水植物的块状根茎为主. 白鹤与白枕鹤属于鹤类, 鸿雁与小天 我岛属于雁鸭类, 在食物喜好与选择上有一定差别, 如鸿雁虽然也以莎草/禾本科草种类为主要食物, 但苦草 
的根茎仍然是鸿雁越冬的首选食物 ${ }^{[26,35-36]}$, 我们认为正是共同食物资源的制约导致研究区域内 4 种鸟类的 种群数量变化呈现出一致的趋势. 在 Barzen 等 “鄱阳湖控湖工程对越冬水鸟数量和分布的潜在影响” 报告 中, 对鄱阳湖主湖区在 $12 、 14$ 和 $16 \mathrm{~m}$ 水位情境下的候鸟适宜生境变化进行了评估,认为在鄱阳湖主湖区水 位 $14 \mathrm{~m}$ 时,适宜各种受食集团水鸟的栖息地面积占整个鄱阳湖区域的比例都达到最大值. 但本文的分析主 要是面向鄱阳湖国家级自然保护区,因此所得结果不能与全湖的结果进行比较 ${ }^{[36]}$.

本文还分年度对不同湖泊的水位与鸟类种群数量的关系进行了深人分析. 对不同年度分析中, 20032005 年 3 个年度的鸟类种群数量与水位关系相似, 都呈现先增多后减少的单峰趋势, 且峰值水位都出现在 $14.75 \sim 14.90 \mathrm{~m}$, 基本保持稳定. 2006 和 2007 年的平均水位升高,鸟类种群数量分布的峰值水位也高于前 3 年. 但由于 3 个湖泊均为浅碟形湖泊,平均水位的升高仍能维持较大面积的受食生境, 因此对种群数量变化 的影响并不明显 ${ }^{[37]}$. 对不同湖泊的分析中, 大湖池和沙湖由于受到良好保护, 且湖泊面积较大 (大湖池 3000 $\mathrm{hm}^{2}$, 沙湖 $1400 \mathrm{hm}^{2}$ ), 均有苦草冬芽分布, 能够为 4 种食块茎鸟类提供充足的食物资源和受食栖息地, 因此, 鸟类种群数量较大且较稳定, 总体趋势变化较小; 而梅西湖虽然也有苦草冬芽分布, 但由于面积较小 (300 $\mathrm{hm}^{2}$ ), 受到人为干扰较大, 年度内和年度间水位变化均较大, 不能充分满足候鸟受食需求, 种群数量变化未 表现出明显的分布规律 ${ }^{[38]}$.

本文揭示了鄱阳湖国家级自然保护区 3 个湖泊 4 种食块茎类鸟类的种群数量与水位之间的关系, 为鄱 阳湖国家级自然保护区的水位管控提供了参考. 4 种食块茎鸟类种群数量变化与鄱阳湖水位的关系在很大 程度上呈现出一致性, 均呈单峰分布; 高种群数量集中分布在水位 $14.5 \sim 15.5 \mathrm{~m}$ 之间, 峰值数量均出现在约 $14.8 \mathrm{~m}$, 且雁鸭类分布水位区间和峰值水位均略高于两种鹤类. 对不同年度水位变化与鸟类种群数量关系 的分析表明,2003-2005 年 3 个年度种群数量峰值出现在 14.75 14.90 m 之间,而 2006 和 2007 年峰值均 出现在 $15.25 \mathrm{~m}$ 附近, 表明随着平均水位升高, 种群数量分布峰值也向高水位移动. 对 3 个湖泊而言, 大湖池 和沙湖鸟类数量高值主要分布在 $14.5 \sim 15.5 \mathrm{~m}$ 之间, 峰值数量大湖池较低, 位于 $14.8 \mathrm{~m}$, 沙湖较高, 位于 $15.2 \mathrm{~m}$, 而梅西湖因人为干扰较大, 未呈现规律性变化. 越冬水鸟种群数量变化是受多因素影响的, 水位只 是其中的一个影响因素 ${ }^{[30]}$,下一步将开展鄱阳湖区域水生植被与水位的关系及其他各种受食集团水鸟对水 位变化响应的研究, 深人了解鄱阳湖水文节律变化对湖区生物的影响.

致谢: 感谢江西鄱阳湖国家级自然保护区管理局和国际鹤类基金会参与该项工作的有关人员.

\section{4 参考文献}

[ 1 ] Ntiamoa-Baidu Y, Piersma T, Wiersma P et al. Water depth selection, daily feeding routines and diets of waterbirds in coastal lagoons in Ghana. Ibis, 1998, 140(1) : 89-103.

[ 2 ] Safran RJ, Colwell MA, Isola CR et al. Foraging site selection by nonbreeding white-faced Ibis. The Condor, 2000,102 (1) : 211-215.

[ 3 ] Bancroft GT, Gawlik DE, Rutchey K. Distribution of wading birds relative to vegetation and water depths in the northern Everglades of Florida, USA. Waterbirds, 2002, 25(3) : 265-277.

[ 4 ] Boertmann D, Riget F. Effects of changing water levels on numbers of staging dabbling ducks in a Danish wetland. Waterbirds, 2006, 29(1): 1-8.

[ 5 ] Desgranges JL, Ingram J, Drolet B et al. Modelling wetland bird response to water level changes in the Lake Ontario-St. Lawrence River hydrosystem. Environmental Monitoring and Assessment, 2006, 113(1/2/3) : 329-365.

[ 6 ] Paracuellos M. How can habitat selection affect the use of a wetland complex by waterbirds? Biodiversity and Conservation, 2006, $15(14)$ : 4569-4582.

[ 7 ] Baker MC. Morphological correlates of habitat selection in a community of shorebirds(Charadriiformes). Oikos, 1979, 33 (1) : 121-126.

[ 8 ] Nudds TD, Bowlby JN. Predator-prey size relationships in North American dabbling ducks. Canadian Journal of Zoology, $1984,62(10)$ : 2002-2008.

[ 9 ] Schroeder LD, Anderson DR, Pospahala RS et al. Effects of early water application on waterfowl production. Journal of Wildlife Management, 1976, 40(2) : 227-232.

[10] Krapu GL, Klett AT, Jorde DG. The effect of variable spring water conditions on mallard reproduction. The Auk, 1983, $100(3)$ : 689-698. 
[11] Powell GVN. Habitat use by wading birds in a subtropical estuary: implications of hydrography. The Auk, 1987, 104 (4) : 740-749.

[12] Lariviere S, Lepage M. Effect of a water-level increase on use by birds of a lakeshore fen in Quebec. Canadian Field-Naturalist, 2000, 114: 694-696.

[13] Holm TE, Clausen P. Effects of water level management on autumn staging waterbird and macrophyte diversity in three Danish coastal lagoons. Biodiversity and Conservation, 2006, 15(14) : 4399-4423.

[14] 刘 影,徐 燕. 三峡工程对鄱阳湖候鸟保护区的影响及对策探讨. 江西师范大学学报: 自然科学版, 1994,18 (4) : 375-380.

[15] Weber LM, Haig SM. Shorebird use of South Carolina managed and natural coastal wetlands. The Journal of Wildlife Management, 1996, 60(1): 73-82.

[16] Safran RJ, Isola CR, Colwell MA et al. Benthic invertebrates at foraging locations of nine waterbird species in managed wetlands of the northern San Joaquin Valley, California. Wetlands, 1997, 17(3) : 407-415.

[17] Davis CA, Smith LM. Ecology and management of migrant shorebirds in the playa lakes region of Texas. Wildlife Monographs, $1998,140: 3-45$.

[18 ] Isola CR, Colwell MA, Taft OW et al. Interspecific differences in habitat use of shorebirds and waterfowl foraging in managed wetlands of California's San Joaquin Valley. Waterbirds, 2000, 23(2) : 196-203.

[19] Colwell MA, Taft OW. Waterbird communities in managed wetlands of varying water depth. Waterbirds, 2000,23 : 45-55.

[20] 熊 舒,纪伟涛,伍旭东等.气温与水位对鄱阳湖越冬雁属鸟类数量变化影响分析一一以湖池、常湖池和朱市湖 为例. 江西林业科技,2011, (1): 1-5.

[21] 吴英豪,纪伟涛. 江西鄱阳湖国家级自然保护区研究. 北京: 中国林业出版社,2002.

[22] Ji WT, Zeng NJ, Wang YB et al. Analysis on the waterbirds community survey of Poyang Lake in winter. Geographic Information Sciences, 2007, 13(1/2): 51-64.

[23] 朱 奇,刘观华,曾南京等. 鄱阳湖自然保护区网络体系建设的探索与尝试. 湿地科学与管理, 2011, 7(3): 29-32.

[24] 王晓鸿,滒帮有,吴国琛. 山江湖工程. 北京:科学出版社,2006.

[25] 胡细英,熊小英. 鄱阳湖水位特征与湿地生态保护. 江西林业科技,2002, (5): 1-4.

[26] 夏少霞,于秀波,范 娜. 鄱阳湖越冬季候鸟栖息地面积与水位变化的关系. 资源科学,2010, 32 (11) : 2072-2078.

[27］纪伟涛,曾南京. 1999 年春鄱阳湖鹤类和大型水禽航空调查报告. 江西林业科技,2000,(5): 22-25.

[28 ] SAS Institute Inc. SAS/STAT User's Guide, Version 8. 0. SAS Institute, Inc., Cary, NC, USA, 1999.

[29] Schimek MG. Smoothing and regression: Approaches, computation, and application. New York: John Wiley \& Sons, 2000.

[30］崔 鹏,夏少霞, 刘观华等. 鄱阳湖越冬水鸟种群变化动态. 四川动物, 2013, 32 (2). doi：1000-7083 (2013) 020000-00.

[31] 胡振鹏, 葛 刚, 刘成林等. 鄱阳湖湿地植物生态系统结构及湖水位对其影响研究. 长江流域资源与环境, 2010,19 (6) : 598-605.

[32] González-Gajardo A, Sepúlveda PV, Schlatter R. Waterbird assemblages and habitat characteristics in wetlands: Influence of temporal variability on species-habitat relationships. Waterbirds, 2009, 32(2) : 225-233.

[33] 刘成林,谭胤静,林联盛等. 鄱阳湖水位变化对候鸟栖息地的影响. 湖泊科学,2011, 23(1): 129-135.

[34] 胡振鹏. 白鹤在鄱阳湖越冬生境特性及其对湖水位变化的响应. 江西科学, 2012, 30 (1) : 30-35.

[35] Lu J. Distribution and bioenergetics of wintering swan geese(Anser cygnoides) in the Yangtze River valley, China. Gibier Fanue Sauvage, 1996, 13: 327-335.

[36] Barzen J, Engels M, Burnham J et al. Potential impact of a water control structure on the abundance and distribution of wintering waterbirds at Poyang Lake. Baraboo: International Crane Foundation, 2009.

[37] 李明辉,李友辉, 熊大衍. 鄱阳湖水利枢纽工程对候鸟栖息环境的影响与对策研究. 江西农业大学学报, 2011, 23 (2) : 153-155.

[38] 罗 浩, 高云云, 于一尊等. 鄱阳湖鸟类和水生植物、透明度和水位生态关系研究. 江西科学, 2010, 28(4): 559-562. 